\title{
A Case Study on the Tourism Community Participation Models of Hainan Ethnic Minority Areas Based on Chinese Targeted Poverty Alleviation Policy
}

\author{
Dan Zhao ${ }^{1}$, Yingqiu $\mathrm{Wu}^{2}$, Xiaoxin $\mathrm{Chen}^{3}$
}

${ }^{1}$ Silk Road Business School, Social construction and cultural development of South China Sea Research center, University of Sanya, Sanya 572000, China;

2 Silk Road Business School, University of Sanya, Sanya 572000, China;

${ }^{3}$ School of Management Finance and Accounting, University of Sanya, Sanya 572000, China;

Keywords: Tourism poverty alleviation; Community participation; Hainan ethnic minority areas; local residents.

Abstract. In Hainan ethnic minority areas where have abundant tourism resources developing pro-poor tourism projects is an important approach to poverty alleviation However whether local residents really participate in tourism is related to the efficiency and effectiveness of the results. So to find the best way for the poor people to fighting poverty and pursuing development, we analysis two different models of Hainan ethnic minority area that they succeed in poverty alleviation through tourism. One is the "New Village Model of Big Region and Small Town" model of Shijin village based on "enterprise + local household" rural amorous feelings towns, the other one is government-led model of the beautiful village of Shihan in Qiongzhong. We attempt to find why they succeed in poverty alleviation through tourism; their ways of community participation, then explores the experiences for reference in the tourism poverty alleviation and development in Hainan ethnic regions. Our results suggest that all the models focus on economic participation and concentrate on getting local residents rich, they emphasize culture, government play an important roles in the initial phase of project, and use "tourism+"in different industries to expand participation breadth and depth.

\section{Introduction}

On November 27, 2015, at the Poverty Alleviation and Development Central Conference, Chinese President Xi Jinping pointed out that "We must work hard to alleviate poverty with precision and focus on improving the effectiveness of poverty eradication" and "really helping the poor". The difficult situation that during tourism poverty alleviation is, the poor are just bystanders who rent tourism resources and didn't really participate in the development and the main beneficiaries are investors. As a rich tourism resources province, Hainan has tried many ways to make the local poor people fully benefit from tourism development, and has emerged a lot of successful tourism projects such as Baoting Shijin Village, Qiongzhong Shihan Village and Penang Valley Li Miao Cultural Tourism Area. However, there are still 446,000 poverty-stricken people and five poverty-stricken regions (Wuzhishan City, Lingao County, Baisha County, Baoting County and Qiongzhong County) and the poverty-stricken population is mainly concentrated in minority areas, where have primary naturally environment and unique multiculturalism cultural. These poor areas choose "tourism" to speeding up poverty alleviation, however, in practice; it has been found that a lot of barriers, such as poor economic conditions, lack of capital, remote location, poor quality of workers and low market access (Clive Poultry, Anna Spenley 2001) prevent poor people from participating in tourism development. At the same time, in the early stage of poverty alleviation, the local poor could get some benefits, but with the further development of tourism, foreign investors moved in and local residents were gradually squeezed out of the tourism economic circle (Nicholson T, 1997). High prices, widening gap between the rich and the poor, changes in folk culture, environmental pollution, and local residents becoming vulnerable groups in the interactive game between capital, rights, culture and emotion ( $\mathrm{Li}$ Jia et al., 2009, Li Yanqin, 2015) becoming increasingly apparent. So, tourism community participation is the most effective way for the poor minority regions to get local residents' maximum benefits. 


\section{Case Study}

\subsection{New Village Model of Big Region and Small Town-Shijin Village, Sandao Town, Baoting Li and Miao Autonomous County.}

Shijin was a poor Li village in Baoting County before tourism development. As the result of natural geographic environment, limited agro-resources, low labor productivity, the education and the economy of Shijing Village was developed at the low level for a long time, in 2009, the village's per capita income was only 2170 Yuan, and there were 12 households still living in thatched houses. The shortage of rural infrastructure of supply and limitation of natural resources restrict the sustainable development of tourism. In 2010, Baoting County put forward a model of "large area small town new village" to promote rural tourism and registered a tourist company. In 2012, villagers moved into new houses for free, and their old houses became a local tourist town with the characteristics of Hainan Li ethnic customs and culture, which have Folk Village History Museum, tourism theme commercial street and projects of green and organic picking tourism. It is a comprehensive rural tourism product chain consisting of "scenic spot sightseeing + small town leisure + rural vacation", and is a new rural tourism model combining Hainan's local characteristics and rustic styles. "Region" refers to tourist attraction and tourist resort area. Shijin Village is very close to folk scenic spot Penang Valley which have extremely scenic of tropical rain forest and attract a lot of tourists, so the village can rely on the Scenic spot to gather tourists and learn their management skills. "Small town" is composed of the village culture tourist area of Blomsey which providing health cares, agricultural picking and experience and comprehensive services. In the whole project, Shijin Village rent land for tourism development, while the company provide all capital and management for development and construction and the specific benefits of the local residents are as follows: the company will build a Li family villa for each household free of charge; rents; their own hotel businesses ;the salary of the Small Town Tourism co, ltd. in Sandaowan region; its own farming in the off-season; dividends from the company; sales of tropical fruits; each household will have a quota for free professional service training. So, according to the local residents' own capital, labor, land, distance from scenic spots, Social capital, national cultural capital and other factors, they can join in tourism economic activities in various ways and could run their own business in tourism.

\subsection{Model of Shihan Village, Hongmao Town, Qiongzhong.}

The village of Shihan, a $\mathrm{Li}$ and Miao minority region, is the highest administrative village in Hainan with a population of 520 from 92 families. Due to its special geographical location and climate, it is not suitable to plant rubber and betel nuts. The villagers' economic mainly depends on planting rice, alpinia oxyphylla and breeding bees. At the end of 2012, Qiongzhong County decided to construct Shihan village as a demonstration site for agricultural tourism which is a new kind of industry combined agriculture with tourism. In 2009, the per capita income of Shihan was only 946 Yuan, while in 2015 it was 8795 Yuan. This mode is composed of "government + county tourism corporation + farmer cooperatives + community residents”. Government is mainly responsible for designing landscape visualization and tourism route, planning spatial structure, publicizing, construction, optimizing development environment, attracting investment. County Tourism Corporation is responsible for tracking guidance, management, business operation and construction of capital operation platform. Farmers' cooperative is mainly responsible for the daily management of farmhouse, organizing $\mathrm{Li}$ and Miao singing and dancing performances, processing and marketing of agricultural and sideline products, and providing accommodation and catering services. Farmers are responsible for maintaining and repairing their traditional houses, providing tourism catering and accommodation services, preserving and inheriting the traditional culture of the nation and the maintenance of the surrounding environment. Everyone can participate in the tourism process in various ways according to his own ability, house, land, capital and skills. It is worth mentioning that they can use their traditional culture to participation, such as choreography and performance of $\mathrm{Li}$ and Miao songs, weave and inheritance of the art of $\mathrm{Li}$ brocade Miao embroidery, produce and sale of local ceramics. So, with the support of government, the Villagers of Shihan benefit from tourism management and tropical agricultural Industry. On the one side, it brings a 
lot income to the villagers; on the other hand, it can protect and inherit the national intangible cultural heritage.

\section{Successful Experience}

\subsection{Economic participation is the core.}

Throughout the two cases, limited by educational level, abilities, and conceptual skills, local residents in ethnic minority areas are mainly concern about the economic participation and less involved in decision-making process. From the perspective of poverty alleviation, the income of local residents has increased significantly after the development of tourism. They use their own land, labor force, geographical location, lifestyle, ethnic customs, pastoral scenery and other capital to participate in the development of tourism, they change their way of production from farmers to shareholders of tourism industry, and their home also change into scenic spots, they could own money not only from agricultural and also from tourism services income, wages, Welfare, green seedling income, special agricultural income, land cooperative income, folk song and dance performance and handicraft sales, commercial pavement, farmhouse entertainment income, ticket bonus and other income together to drive the rich situation.

\subsection{National culture participation}

The multi-ethnic agglomeration makes it possible for the residents of Hainan community to participate in the service fields and National culture fields, their distinctive culture is their productive forces, folk dancing, festivals, handicraft, traditional building, the art of weaving, customs of production and life, religious belief and tradition, sports activities, all of these is a unique tourist resource and can attracting many tourists. In the two cases, the local residents have not been moved out of the scenic spots or villages; some of them just show their national daily life and work contents that would give them some incomes from the tourism industry.

\subsection{Government play an important role}

Due to geographical and regional endowments, the economic development of ethnic minority areas in Hainan Province is relatively backward, and the ideology and participation ability of community residents are relatively low. Even though the willingness to participate is very strong, the lack of economic, social resources, information are the important factors hampering their participation in tourism planning and decision-making, which requires the government to intervene in the development in order to improving traffic environment, design the new folk house, making new policy, attract the investors.

\section{Summary}

There is no doubt that community participation in tourism is an effective way to achieve the goal of poverty alleviation. It is the fundamental guarantee for ensuring the maximum income of the poor. The local residents should be the main developers and operators, meanwhile, they can promote selfconfidence, seek opportunities, develop some skills and abilities in tourism which they can use to find some good jobs and run their own business, and this is the real sustainable way for them to get rid of poverty and become rich. Through analysis of the three successful demonstration projects of tourism poverty alleviation in Hainan's minority areas, this paper summarizing the experiences and proposes the suggestion of effective incentive system and industry combination to the poor minority regions, so as to ensure the poor residents maximum participate in tourism development to get their biggest benefits.

\section{Acknowledgment}

This article is funded by Hainan Education Department Project: The ways of exaltation and promotion the local residents' participation abilities in tourism development (Project number: HNKY2016-47), Hainan Social Sciences Association Key Research Base funding project: Public participation in the 
ecological environment management of villages in Hainan from the perspective of Rural Revitalization Strategy (Project number: HNSK (JD) 18-05)

\section{References}

[1] Simmons D G. Community participation in tourism planning [J]. Tourism Management, 1994, 15(2):98-108.

[2] Verdonschot M M, de Witte L P, Reichrath E, et al. Community participation of people with an intellectual disability: a review of empirical finding.[J]. Journal of Intellectual Disability Research, 2010, 53(4):303-318.

[3] Tosun C. Expected nature of community participation in tourism development [J]. Tourism Management, 2006, 27(3):493-504. 